\title{
Influence of Propylene Glycol Concentrations in Mangostin Pericarp Extract Gels Formulation: Gels Physical Characteristics, Antibacterial Activity Against Staphylococcus aureus, and Functional Antioxidant Activity Based on Radical 2,2-diphenyl-1-picrylhydrazyl Scavenging Activity
}

\author{
Rina Kuswahyuning*, Sylvia Utami Tunjung Pratiwi, Joselin Ekaputri, Meiliana \\ Faculty of Pharmacy, Universitas Gadjah Mada, Yogyakarta, Indonesia
}

\begin{abstract}
Mangostin (Garcinia mangostana L.) fruit pericarp (GMP) extract has been shown to have antimicrobial and antioxidant activities. This study aimed to formulate and evaluate gel formulations of GMP extract using sodium carboxymethylcellulose as a gelling agent and propylene glycol (PG) in varying concentrations (i.e. $0-40 \%$ ). GMP extract was evaluated for total mangostin content and antioxidant activity based on 2,2-diphenyl-1-picrylhydrazyl (DPPH) radical scavenging method. Physical gel characteristics were also examined. All gels had similar $\mathrm{pH}$ and spreadability, however, gel with 40\% PG produced significantly lower viscosity. Antibacterial activities against S.aureus were shown to be the same among GMP extract gels. The antioxidant activity of all GMP extract gels could be confirmed based on the radical DPPH scavenging method. PG content of $40 \%$ significantly reduced the increase of GMP extract gel viscosity after being stored for four weeks at room temperature. Additionally, the lowest syneresis was also shown for GMP extract gel with $40 \%$ PG content.
\end{abstract}

Keywords: Mangostin fruit pericarp extract; gel; propylene glycol; antibacterial; antioxidant

\section{INTRODUCTION}

Topical products that promote healthy skin have been explored and developed continuously. As the outer part of the human body, skin continuously exposes to exogenous stimuli such as bacterial pathogens as well as ultraviolet light. Botanical extract rich in polyphenols content offers a great material source for topical application. Studies documented that polyphenols have remarkable antimicrobial and antioxidant activities. High polyphenols content can be found, for example, in some of the fruit peel such as pericarp of mangostin (Garcinia mangostana L.) fruit. It has been used traditionally mostly in the Southeast Asia region for skin infection and wound therapy (Obolskiy et al., 2009). The pericarp of mangostin fruit has a high content of xanthones, a class of polyphenolic compound, which posses many pharmacological activities including antimicrobial and antioxidant (Obolskiy et al., 2009, Suttirak and Manurakchinakorn, 2014)

A gel is a popular semisolid product in topical pharmaceutical as well as cosmetic products. It offers several benefits such as less greasy, good emolliency, easily spreadable, and easily removed. In gel formulation development,

*Corresponding author : Rina Kuswahyuning

Email : rinakus@ugm.ac.id designing formulation composition is a crucial process. The study shows the significance of vehicle composition on the efficacy and acceptability of topically applied products (Shukr and Metwally, 2013).

Being one of the key components in a gel formulation, the gelling agent has been shown to determine gel appearance, viscosity, $\mathrm{pH}$, and spreadability. Furthermore, the extent and rate of drug release from gel formulations were also influenced (Helal et al., 2012). Sodium carboxymethylcellulose ( $\mathrm{Na} \mathrm{CMC}$ ) is a cellulose derived gelling agent used in topical gel formulations (Maswadeh et al., 2006, Ghorpade et al., 2012). Shukr and Metwally (2013) used Na CMC, carbopol 940, and hydroxypropylmethylcellulose as gelling agents to formulate lemongrass oil gel for antibacterial activity. $\mathrm{Na}$ CMC-based gel was shown to have superior spreadability among other gels, however, its antibacterial activity was lower than that of carbopol 940-based gel.

PG is a widely used excipient in a gel formulation. It is usually included in gel formulation as a humectant, co-solvent, and/or penetration enhancer (Shukr and Metwally, 2013). While its inclusion in formulation could aid in chemical solubilization, to some degree, PG could affect drug release (Güngör and Bergișadi, 2004). 
Table I. GMP extract gel composition

\begin{tabular}{lcccc}
\hline \multirow{2}{*}{ Formulation } & \multicolumn{4}{c}{ Gel Compositions (\%) } \\
\cline { 2 - 5 } & F1 & F2 & F3 & F4 \\
\hline Mangostin fruit pericarp extract & 20 & 20 & 20 & 20 \\
Sodium carboxymethylcellulose & 2 & 2 & 2 & 2 \\
Propylene glycol & 0 & 10 & 20 & 40 \\
Methylparaben & 0.10 & 0.10 & 0.10 & 0.10 \\
Water & 77.9 & 67.9 & 57.9 & 37.9 \\
\hline
\end{tabular}

Lower antibacterial activity of Na CMC-based gel containing PG has been reported (Shukr and Metwally, 2013). PG concentration in topical gel needs to be carefully chosen.

This research aimed to formulate GMP extract gel using $\mathrm{Na} \mathrm{CMC}$ as the gelling agent and to evaluate the influence of gel composition varying in PG concentrations. Physical gel characteristics i.e. visual homogeneity, $\mathrm{pH}$, viscosity, spreadability, and syneresis were examined. The influence of PG content in GMP extract gels on their antimicrobial activity was investigated using Staphylococcus aureus as the microbial model. Additionally, since GMP extract has been reported to have antioxidant activity, the functional antioxidant activity of GMP extract and the gels were also tested based on DPPH radical scavenging activity method. Changes in gel physical characteristics were followed after 4 weeks of storage at room temperature.

\section{METHODOLOGY \\ Materials}

Dried Garcinia Mangostana Pericarp (GMP) extract was extracted using 70\% ethanol (batch number 111PP01.2 purchased from PT. Borobudur Plant). The $\alpha$-mangostin (analytical grade, purity of 96\%) and 2,2-diphenyl-1-picrylhydrazyl radical (DPPH) were bought from Sigma Aldrich. Ethanol and methanol were analytical grade \& purchased from E Merck. Sodium Carboxymethylcellulose (Na $\mathrm{CMC}$ ), propylene glycol (PG), methylparaben, were pharmaceutical grade and purchased from the local store (local supplier).

\section{Methods}

Quantification total mangostin in GMP extract

Mangostin in GMP extract was quantified based on the UV spectrophotometry method (Pothitirat and Gritsanapan, 2008, Aisha et al., 2013). Briefly, the calibration curve was made using $\alpha$-mangostin as a reference. $\alpha$-mangostin was weighed and diluted with methanol to make a concentration of $200 \mu \mathrm{g} / \mathrm{mL}$. From this stock solution, a range of $\alpha$-mangostin concentrations of
$0,20-12,00 \mu \mathrm{g} / \mathrm{mL}$ was made. The absorbance of each concentration was made at a maximum wavelength $(320 \mathrm{~nm})$. GMP extract was weighed (200 mg), added with PG in a volumetric flask to make a volume of $10 \mathrm{~mL}$ and sonicated (15 min). The sample was taken, diluted 250-times with methanol, and the absorbance was measured at the maximum wavelength (Kuswahyuning et al., 2019).

\section{GMP extract gel formulations}

GMP extract gels composition is presented in Table I. Dry GMP extract was added with water (F1) or PG (F2, F3, and F4) then mixed and sonicated. Na CMC, which had been hydrated overnight, stirred and added with methylparaben and water. GMP extract dispersion was slowly added to the gel base with continuous stirring (750 $\mathrm{rpm}, 10 \mathrm{~min}$ ). Four GMP extract formulations with composition similar to Table I but without a gelling agent (Na CMC) were also made for antibacterial test purpose, namely FWG1 FWG2, FGW3, and FWG 4.

\section{Antioxidant activity based on radical DPPH scavenging method}

GMP extract antioxidant activity was evaluated based on a previously published study (Kuswahyuning et al., 2019). Briefly, GMP extract was prepared at concentrations of $2-27 \mu \mathrm{g} / \mathrm{ml}$. Sample $(0.1 \mathrm{ml})$ was added with ethanol $(1 \mathrm{ml})$, acetate buffer pH $5.5(1 \mathrm{ml})$, and ethanolic DPPH solution $(0.4 \mathrm{mM} 0.5 \mathrm{ml})$. The reaction mixture was measured after $30 \mathrm{~min}$ at the maximum wavelength $(522 \mathrm{~nm})$. The result was expressed as concentration GMP extract that result in 50\% radical DPPH scavenging activity $\left(\mathrm{IC}_{50}\right)$.

GMP extract gels were also assessed using radical DPPH scavenging activity. The gel was weighed $(100 \mathrm{mg})$ and added with $20 \%$ ethanol to make a volume of $10 \mathrm{ml}$. Following appropriate dilution (5-times), sample $(0.1 \mathrm{ml})$ was tested for DPPH scavenging activity as described above. The final concentration of GMP extract in the reaction medium was $9.6 .10^{-3} \mathrm{mg} / \mathrm{ml}$. GMP extract as raw 
material was also tested as the method above. Additionally, the GMP extract-free formulation was also tested.

\section{In vitro antibacterial activity}

Staphylococcus aureus was incubated in a sterile Nutrient Broth (NB) at $37^{\circ} \mathrm{C}$ for $24 \mathrm{~h}$. $S$. aureus was diluted with $\mathrm{NB}$ to make a concentration of $1 \times 10^{7} \mathrm{CFU} / \mathrm{ml}$. One hundred microliters of $1 \times 10^{7} \mathrm{CFU} / \mathrm{ml}$ of bacterial inoculum was poured on a plate and added with Nutrient Agar (NA) (10 ml) to make $S$. aureus suspension of $1 \times 10^{5} \mathrm{CFU} / \mathrm{ml}$. Wells (5 mm) were put in the NA. Forty microliters of formulations were loaded into the wells then incubated at $37^{\circ} \mathrm{C}$ for $24 \mathrm{~h}$. The diameters of the clear zone that indicated the inhibition zones were measured. GMP extract gel base (without GMP extract) was also tested. 1\% of chloramphenicol was used as a reference. Results were the average of three replicates.

\section{GMP extract physical gel evaluations}

Visual homogeneity

Gel visual homogeneity was evaluated based on visual inspection after the gels have been set in the container. The presence and appearance of any aggregates were inspected.

\section{pH evaluation}

The gel was weighed (1 g) and added with water to make a volume of $10 \mathrm{ml}$. $\mathrm{pH}$ was measured using a calibrated $\mathrm{pH}$ meter. Results were the average of three replicates.

\section{Viscosity}

Viscosity was measured using a viscometer (Brookfield DV-1 prime) with a spindle no. 6 at 100 rpm. Results were the average of three replicates.

\section{Syneresis}

Gel (10 g) was put into a pre-weighed glass container and sealed with a plastic wrap film. The glass containers containing gel were stored at $10^{\circ} \mathrm{C}$ for predetermined periods i.e. 24, 48, 72 h. Each period, the container was taken and water condensed on the glass container was removed with tissue paper then weighed with an analytical balance. All measurements were conducted in triplicates. Syneresis (\%) was calculated as the weight difference between initial gel weight and weight after treatment (Kuncari et al., 2014). Results were the average of three replicates.

\section{Spreadability}

The spreadability of the gel was evaluated by weighing the gel $(0.5 \mathrm{~g})$ and placed in the middle of the scaled round glass plate. Another glass plate was put on top of the gel and given a total load of $150 \mathrm{~g}$ for a predetermined time (total of $7 \mathrm{~min}$ ). Spreadability was measured as the length of the diameter of the spread gel (Helal et al., 2012). Results were the average of three replicates.

\section{Physical stability of GMP extract gels}

GMP extract gel formulations were kept in a sealed plastic container and stored at room temperature $\left(28 \pm 2^{\circ} \mathrm{C}\right)$ for 28 days. During predetermined time i.e. $1,3,5,7,21$, and 28 days, formulations were evaluated for physical stability i.e. $\mathrm{pH}$, spreadability, and viscosity.

\section{Data/Statistical analysis}

All of the data was expressed as mean \pm SD (standard deviation). One-way ANOVA followed by the Tukey test was performed for the statistic analysis. A significance level was set at $p<0.05$.

\section{RESULT AND DISCUSSION}

Mangostin fruit pericarp contains xanthones such as $\alpha$-mangostin, $\beta$-mangostin, and $\gamma$-mangostin. The major constituent in mangostin peel was identified as $\alpha$-mangostin, which was reported to have antimicrobial and antioxidant activities. Quantification total mangostin from GMP extract and GMP dry powder has been successfully done based on the UV-spectrophotometric method (Pothitirat and Gritsanapan, 2008, Aisha et al., 2013) and High-Performance Liquid Chromatography (Pothitirat and Gritsanapan, 2009). The UV-spectrophotometric method was suggested as a quick and simple method to quantify total mangostin from GMP pericarp extract. Using the UV-spectrophotometric method, the present result showed total mangostin in dried GMP extract was $21,16 \pm 0,01 \%$. Other studies reported content total mangostin from GMP extract of 35.68 - 36.92\% (Pothitirat and Gritsanapan, 2008). The difference in the extract production method (e.g. extracting solvent) as well as the source of the material (e.g. place of growth, maturity stage, harvesting period) could be the reason for total mangostin content discrepancy.

Mangostin in GMP extract has been shown to have antibacterial (Obolskiy et al., 2009) as well as antioxidant activities (Tjahjani et al., 2014, Suttirak and Manurakchinakorn, 2014). In terms of antibacterial activity, a study by Sukatta et al. (2008) reported that GMP extract gel was tested against pathogens such as Staphylococcus aureus, Staphylococcus epidermidis, and Propionibacterium acnes. It was shown that GMP extract gel was able to inhibit the growth of all of those pathogens tested but more effective in inhibiting Saureus growth. The present study confirmed that GMP 
Table II. GMP extract gels characteristics

\begin{tabular}{clccc}
\hline Formulation & $\begin{array}{c}\text { Visual } \\
\text { appearance } \\
\text { homogeneity }\end{array}$ & Viscosity (mPas) & pH & Spreadability (cm) \\
\hline F1 & Homogeneous & $3343,33 \pm 100,17$ & $5,25 \pm 0,19$ & $6.42 \pm 0.33$ \\
F2 & Homogeneous & $3226,67 \pm 109,70$ & $5,30 \pm 0,26$ & $6.22 \pm 0.88$ \\
F3 & Homogeneous & $3636,67 \pm 232,45$ & $5,2 \pm 0,06$ & $6.03 \pm 0.25$ \\
F4 & Homogeneous & $2803,33 \pm 89,63$ & $5,07 \pm 0,02$ & $6.82 \pm 0.28$ \\
\hline
\end{tabular}

extract showed S.aureus antibacterial activity with an average inhibition diameter zone of $14 \pm 1 \mathrm{~mm}$. A major constituent in GMP extract, i.e. $\alpha$ mangostin, has also been reported to inhibit S.aureus (Al-Massarani et al., 2013).

Evaluation of antioxidant activity from botanical extract can be evaluated based on several methods including DPPH radical scavenging activity. It is based on antioxidant activity to donate a hydrogen atom to capture radical DPPH (Suttirak and Manurakchinakorn, 2014). Sukatta et al. (2013) reported that radical DPPH antioxidative activity of the pericarp of mangosteen fruit was related to $\alpha$-mangostin and $\gamma$-mangostin. Dried GMP extract used in this study was extracted using $70 \%$ ethanol and showed $\mathrm{IC}_{50}$ (concentration which shows $50 \%$ radical DPPH scavenging activity) of $14.94 \pm 0.26 \mu \mathrm{g} / \mathrm{mL}$. This IC 50 value was lower than that of reported by Tjahjani et al. (2014) who reported an $\mathrm{IC}_{50}$ of $6.56 \pm 0.31 \mu \mathrm{g} / \mathrm{mL}$ of GMP ethanolic extract, possibly because of the difference in extract material source and or harvesting time.

To develop topical GMP extract gel formulations, vehicle composition needs to be carefully considered. Some studies reported the use of $\mathrm{Na}$ CMC as a gelling agent with a concentration of $0.5-2 \%$ (Verma et al., 2013) and 23\% (Shukr and Metwally, 2013). It is of interest to note that those studies consisted of drugs, Na CMC, PG, and water. The discrepancy gel physical properties, as well as drug release in each of these two studies, were related to $\mathrm{Na} \mathrm{CMC}$ and $\mathrm{PG}$ concentration.

In this study, Na CMC was used at a fixed concentration i.e. $2 \%$ since the preliminary experiment showed that at this concentration it produced GMP extract gel with desired viscosity. The study investigated GMP extract loaded gels differing in PG content i.e. 0-40\% and its effects on GMP extract gel physicochemical characteristics as and antimicrobial activity. PG is one of the most popular components in topically applied product functioning for example as emollient, humectant, and co-solvent. In gel formulations studies, PG was included in formulations in varying concentrations ranging from 1-20 (Patel et al., 2011, Jambaninj et al., 2012, Helal et al., 2012). Other studies also reported at higher $\mathrm{PG}$ concentrations i.e. $70 \%$ (Diez-Sales et al., 2005).

Evaluation gel physicochemical properties i.e. visual inspection, viscosity, $\mathrm{pH}$, and spreadability resulted in data presented in Table II. Assessment of these formulation characteristics is necessary for relation to product quality. All of the gels showed a browny color and visually homogeneous. The $\mathrm{pH}$ of all formulations was similar $(\mathrm{p}>0.05)$ showing average value between 5.07-5.30. A topical product is usually required to have a pH around 4.5-6.5 which is suitable for skin application (Shukr and Metwally, 2013). In terms of viscosity, the gels had an average viscosity range of 2803.33 - 3636.67 mPas. PG content of 10 and $20 \%$ did not significantly cause changes in the viscosity $(\mathrm{p}>0.05)$ compared with gel without PG. However, a significantly reduced viscosity was observed with $40 \%$ PG content $(\mathrm{p}<0.05)$. This result is in agreement with Arellano et al. (1999) who found that PG concentration in the gel up to $30 \%$ did not result in significant changes in viscosity. Gel viscosity was decreased when PG concentration in the gel higher than $30 \%$. Although PG concentration influenced gel's viscosity, the spreadabilities of GMP extract gels were not statistically different among formulations ( $p>0.05)$ showing an average spreadability value of 6.03$6.82 \mathrm{~cm}$. This spreadability is higher than that of reported for fluconazole gel i.e. 3-5 cm (Helal et al., 2012). Figure 1 presents the syneresis of the GMP extract gels. All of the formulations showed higher weight loss after $72 \mathrm{~h}$. The average weight loss of F1, F2, F3, and F4 were 3.37, 1.95, 1.17, and 0.37\%, respectively. Increasing PG content in the gels significantly reduced syneresis $(\mathrm{p}<0.05)$.

The antimicrobial activity of GMP extract formulations was tested against S.aureus. The result is presented in Table III. S.aureus is a grampositive bacteria that causes superficial skin infection (Daum, 2007). GMP extract formulations showed inhibition activity on $S$. aureus. The average diameter inhibition of F1, F2, F3, and F4 was $11.66,13.33,13$, and $12.33 \mathrm{~mm}$, respectively, 


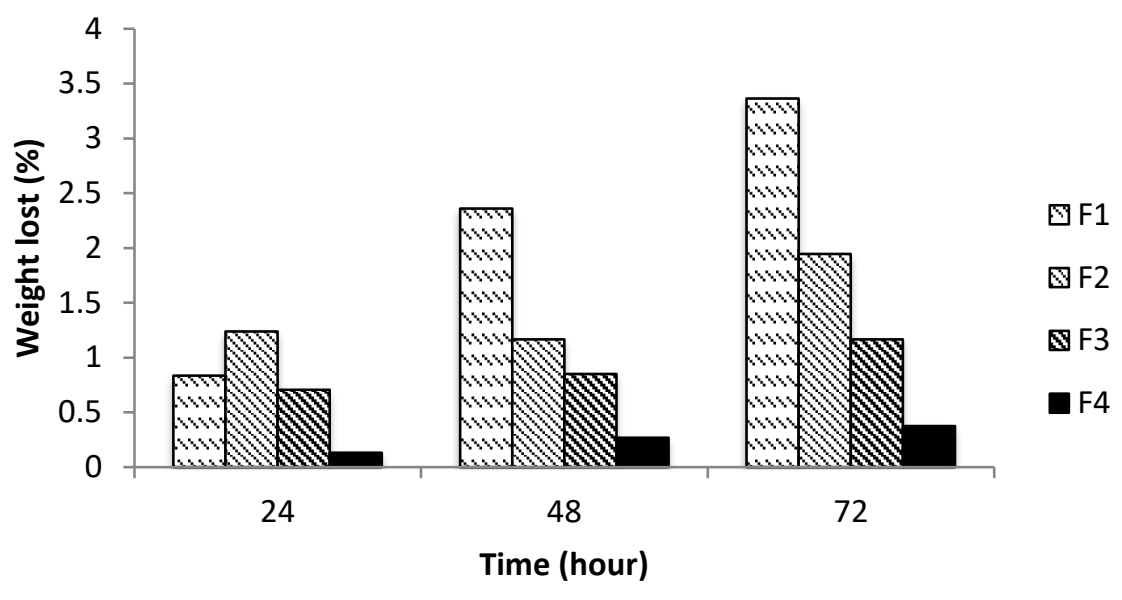

Figure 1. Syneresis of the GMP extract gels

Table III. In vitro antibacterial activity against S.aureus of GMP extract gels (F1-F4) and GMP extract formulations without CMC Na (FWG1-FWG4)

\begin{tabular}{cc}
\hline Formulation & Inhibition diameter (mm) \\
\hline F1 & $11.66 \pm 0.57$ \\
F2 & $13.33 \pm 0.57$ \\
F3 & $13.00 \pm 2.00$ \\
F4 & $12.33 \pm 0.58$ \\
Gel Base & - \\
Chloramphenicol $(1 \%)$ & $38.67 \pm 1.15$ \\
FWG1 & $14.00 \pm 1.00$ \\
FWG2 & $13.66 \pm 0.57$ \\
FWG3 & $13.00 \pm 0.53$ \\
\hline
\end{tabular}

whereas that of the gel base did not show any inhibition. The concentration of PG content in the gels did not significantly affect the inhibitory activity against $S$. aureus ( $\mathrm{p}>0.05)$. Formulations with PG addition i.e. F2, F3, and F4 produced similar S.aureus zone inhibition compared to gel without PG (F1). In vitro antimicrobial activity is related to the extent of drug release. The good antimicrobial activity is correlated with high drug release (Shahin et al., 2011). Since GMP extract concentration in all gels was kept constant, the difference PG content in the gel was the main factor that affected the antimicrobial activity of the GMP extract gels. PG has been reported to influence drug solubility as well as vehicle viscosity. Thus difference PG content in GMP extract gels might cause changes not only in drug solubility but also in vehicle viscosity. PG influence on GMP extract solubility in the formulations is difficult to be justified as it was not measured in this study. In terms of viscosity, even though $40 \%$ PG in GMP extract gel caused significantly reduced viscosity but its antibacterial activity was similar compared with all other gels. Drug diffusivity in the formulations may be more related to the microviscosity of the vehicle rather than its macroviscosity (Diez-Sales et al., 2005). Since gel viscosity might also be affected by the presence of gelling agent, to eliminate gelling agents influence, more tests on antimicrobial activity against S.aureus were also done using GMP extract formulations produced without gelling agent addition. The results demonstrated a relatively similar S.aureus inhibition zone from all formulas without a gelling agent. However, Formulation FWG1 had a significantly higher S.aureus inhibition zone compared to formulation F1. It suggested that the presence of gelling agent CMC-Na in F1 was responsible for the reduction of antimicrobial activity. Interestingly, FWG2, FWG3, and FWG4 demonstrated similar S.aureus inhibition zones. Further study is needed to evaluate GMP extract solubility as well as vehicle viscosity due to PG concentrations.

The developed GMP extract gels were also tested for their functional antioxidant activity 


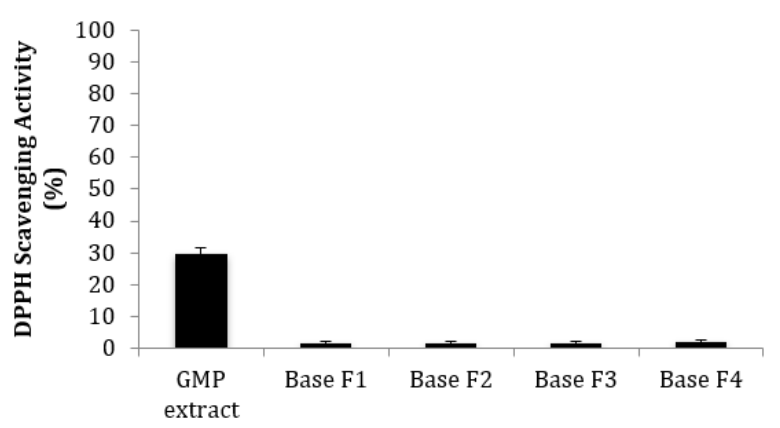

(A)

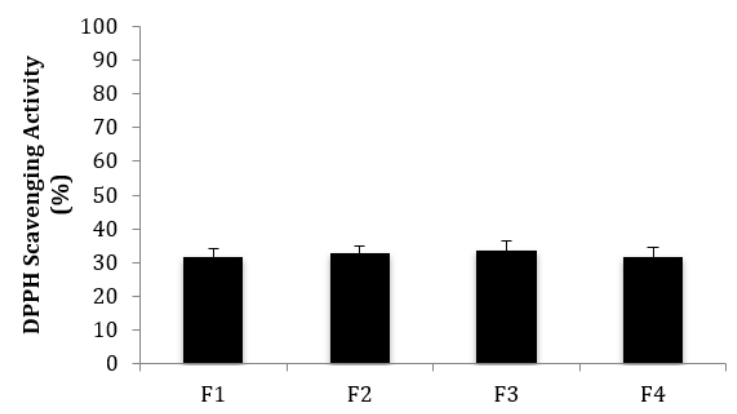

(B)

Figure 2. The radical DPPH scavenging activity of (A) GMP extract and gel bases (free of GMP extract); (B) GMP extract gels

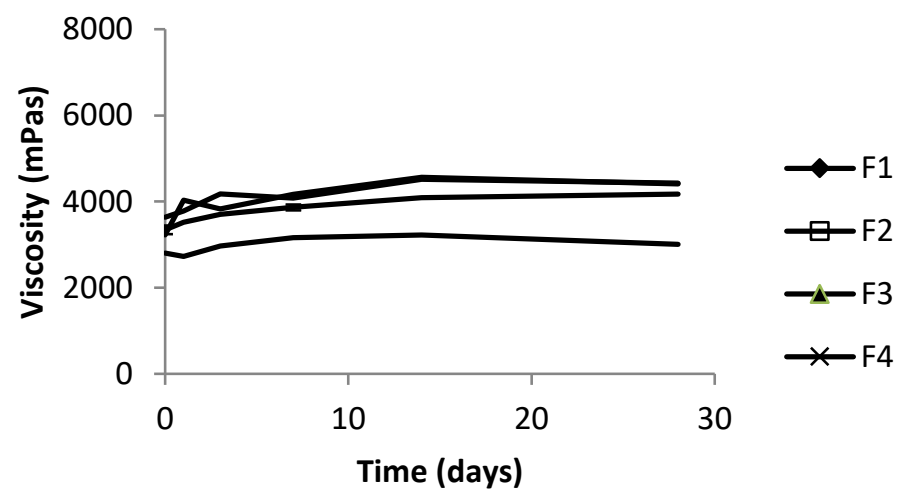

Figure 3. The viscosity of the GMP extract gels when stored at room temperature for 28 days

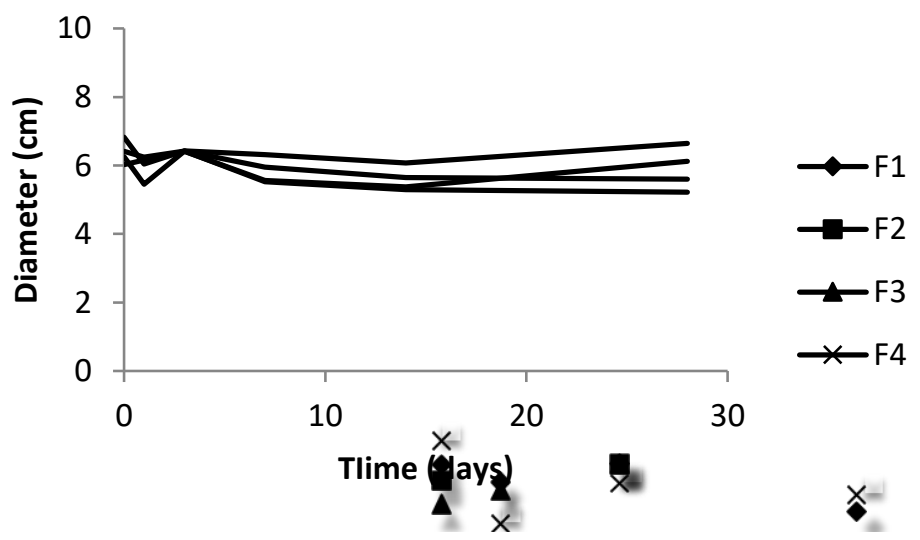

Figure 4. Spreadability of the GMP extract gels when stored at room temperature for 28 days

based on radical DPPH scavenging activity. It has been shown as a valuable tool to confirm if the formulation has antioxidant activity. Antioxidant activity evaluation based on the DPPH method has been suggested as a suitable method for formulations containing natural products which usually consists of a complex polyphenolic mixture compound (Fonseca et al., 2011). The adequacy of the DPPH scavenging method to assess the functional antioxidant activity of GMP extract gel was first tested. Each of the formulations without GMP extract addition (each of gel base) showed no significant influence on DPPH scavenging activity (Figure 2). It suggested that components of gel formulations did not interfere with the DPPH scavenging assay confirming the application of the radical DPPH scavenging method for evaluating antioxidant activity in the 
formulations. GMP extract demonstrated radical DPPH scavenging activity of $29.31 \pm 2.31 \%$. Compared to the same final concentration in the reaction medium, all of the formulations resulted in similar radical scavenging activity ( $p>0.05$ ) of $31.43-33.25 \%$, which suggests that antioxidant activity was maintained in all of GMP extract gels.

A preliminary stability study is usually evaluated during the early formulation development process to detect any instability that might occur. Physical gel stability was evaluated at room temperature storage for a period of 28 days. The changes in viscosity of the formulations during 28 days of storage at room temperature are shown in Figure 3. All of the formulations showed a significant increase in viscosity after being stored for 28 days $(\mathrm{p}<0.05)$ showing average viscosity value of 4173, 4406, 4426, and $3006 \mathrm{mPas}$ for F1, F2, F3, and F4, respectively. There was a marked difference in the extent of the percentage increase of viscosity. Formulation F4, which had the highest content of PG, showed the lowest increase of viscosity. This result is consistent with the lowest syneresis shown from F4. In terms of $\mathrm{pH}$, after 28 days of storage, F1, F2, F3, and F4 showed average $\mathrm{pH}$ values of 5.50, 5.02, 5.41, and 6.06, respectively. Even though there were relatively slight changes in $\mathrm{pH}$ values, all of the $\mathrm{pHs}$ of the formulations were still within a suitable $\mathrm{pH}$ for topical application. Spreadability values were only slightly decreased within 28 days of observation.

\section{CONCLUSION}

GMP extract gels formulated with variation in PG concentrations influenced physical gel characteristics differently. Spreadability and $\mathrm{pH}$ of the formulations were similar, however, viscosity was significantly decreased in GMP extract gel containing $40 \%$ PG. Interestingly, the antibacterial activity of all GMP extract gels against S.aureus was relatively the same. All GMP extract gels also showed antioxidant activity tested based on radical DPPH scavenging activity. Following storage at room temperature for four weeks, all GMP extract gels had unchanged spreadability and $\mathrm{pH}$ value but significantly changed in viscosity and syneresis. PG concentration of $40 \%$ produced significantly reduced syneresis and viscosity changes in GMP extract gel stored at room temperature for four weeks.

\section{ACKNOWLEDGMENT}

The authors wish to thank the Faculty of Pharmacy, Universitas Gadjah Mada, for the research grant "Hibah Penunjang Penelitian Dasar
2017". Some of the data was used by Joselin Eka Putri and Meiliana to obtain their academic degree.

\section{REFERENCES}

Aisha, A. F., Abu-Salah, K. M., Ismail, Z. \& Majid, A., 2013, Determination of total xanthones in garcinia mangostana fruit rind extracts by ultraviolet (uv) spectrophotometry. J Med Plants Res, 7, 29-35.

Al-Massarani, S. M., El Gamal, A. A., Al-Musayeib, N. M., Mothana, R. A., Basudan, O. A., Al-Rehaily, A. J., Farag, M., Assaf, M. H., El Tahir, K. H. \& Maes, L., 2013, Phytochemical, antimicrobial and antiprotozoal evaluation of garcinia mangostana pericarp and $\alpha$-mangostin, its major xanthone derivative. Molecules, 18, 10599-10608.

Arellano, A., Santoyo, S., Martın, C. \& Ygartua, P., 1999, Influence of propylene glycol and isopropyl myristate on the in vitro percutaneous penetration of diclofenac sodium from carbopol gels. Eur J Pharm Sci, 7, 129-135.

Daum, R. S., 2007, Skin and soft-tissue infections caused by methicillin-resistant staphylococcus aureus. N Engl J Med, 357, 380-390.

Diez-Sales, O., Garrigues, T., Herraez, J., Belda, R., Martin-Villodre, A. \& Herraez, M., 2005, In vitro percutaneous penetration of acyclovir from solvent systems and carbopol 971-p hydrogels: Influence of propylene glycol. $J$ Pharm Sci, 94, 1039-1047.

Fonseca, Y. M., Catini, C. D., Vicentini, F. T., Cardoso, J. C., Junior, R. L. C. D. A. \& Fonseca, M. J. V., 2011, Efficacy of marigold extract-loaded formulations against uv-induced oxidative stress. J Pharm Sci, 100, 2182-2193.

Ghorpade, V., Mali, K., Dias, R. \& Karande, P., 2012, Carbopol and sodium carboxymethylcellulose based methylsulfonylmethane gels for treatment of osteoarthritis: In-vitro and in-vivo evaluation. Ind J Pharm Edu Res, 46, 235.

Güngör, S. \& Bergişadi, N., 2004, Effect of penetration enhancers on in vitro percutaneous penetration of nimesulide through rat skin. Pharmazie, 59, 39-41.

Helal, D. A., El-Rhman, D. A., Abdel-Halim, S. A. \& ElNabarawi, M. A., 2012, Formulation and evaluation of fluconazole topical gel. Int J Pharm Pharm Sci, 4, 176-183.

Jambaninj, D., Sulaiman, S. a. S., Gillani, S. W., Davaasuren, T., Erdenetsetseg, G. \& Dungerdorj, D., 2012, Technological study of preparing gel from semi-solid extract of 
cacalia hastata l. J. Adv. Pharm. Technol. Res., $3,25$.

Kuncari, E. S., Iskandarsyah, I. \& Praptiwi, P., 2014, Evaluasi, uji stabilitas fisik dan sineresis sediaan gel yang mengandung minoksidil, apigenin dan perasan herba seledri (apium graveolens l.). Buletin Penelitian Kesehatan, $42,213-222$.

Kuswahyuning, R., Yuniarti, N., Lesmana, I. \& Fadhilah, N., 2019, In-vitro transport evaluation of garcinia mangostana $l$. Pericarp extract loaded cream and gel. Int J Pharm Sci Res, 10, 3715-3722.

Maswadeh, H. M., Semreen, M. H. \& Naddaf, A. R., 2006, Anti-inflammatory activity of achillea and ruscus topical gel on carrageenaninduced paw edema in rats. Acta Pol Pharm, 63, 277-280.

Obolskiy, D., Pischel, I., Siriwatanametanon, N. \& Heinrich, M., 2009, Garcinia mangostana l.: A phytochemical and pharmacological review. Phytother Res, 23, 1047-1065.

Patel, J., Patel, B., Banwait, H., Parmar, K. \& Patel, M., 2011, Formulation and evaluation of topical aceclofenac gel using different gelling agent. Int J Drug Dev Res, 3, 156-164.

Pothitirat, W. \& Gritsanapan, W., 2008, Quantitative analysis of total mangostins in garcinia mangostana fruit rind. J Health Res, $22,161-166$.

Pothitirat, W. \& Gritsanapan, W., 2009, Hplc quantitative analysis method for the determination of $\alpha$-mangostin in mangosteen fruit rind extract. Thai Journal of Agricultural Science, 42, 7-12.
Shahin, M., Abdel Hady, S., Hammad, M. \& Mortada, N., 2011, Novel jojoba oil-based emulsion gel formulations for clotrimazole delivery. AAPS PharmSciTech, 12, 239-247.

Shukr, M. \& Metwally, G. F., 2013, Evaluation of topical gel bases formulated with various essential oils for antibacterial activity against methicillin-resistant staphylococcus aureus. Trop J Pharm Res, 12, 877-884.

Sukatta, U., Rugthaworn, P., Pitpiangchan, P. \& Dilokkunanant, U., 2008, Development of mangosteen anti-acne gel. Kasetsart J.(Nat. Sci), 42, 163-168.

Sukatta, U., Takenaka, M., Ono, H., Okadome, H., Sotome, I., Nanayama, K., Thanapase, W. \& Isobe, S., 2013, Distribution of major xanthones in the pericarp, aril, and yellow gum of mangosteen (garcinia mangostana linn.) fruit and their contribution to antioxidative activity. Biosci. Biotechnol. Biochem., 77, 984-987.

Suttirak, W. \& Manurakchinakorn, S., 2014, In vitro antioxidant properties of mangosteen peel extract. J Food Sci Technol, 51, 3546-3558.

Tjahjani, S., Widowati, W., Khiong, K., Suhendra, A. \& Tjokropranoto, R., 2014, Antioxidant properties of garcinia mangostana 1 (mangosteen) rind. Procedia Chem, 13, 198203.

Verma, A., Singh, S., Kaur, R. \& Jain, U. K., 2013, Formulation and evaluation of clobetasol propionate gel. Asian J Pharm Clin Res, 6, 1518. 